\title{
Incursões marxistas
}

\author{
MAURÍCIO CHALFIN COUTINHO
}

\begin{abstract}
A INFLUÊNCIA DO marxismo no pensamento econômico brasileiro é um tema que se pode tratar a partir de duas perspectivas. A primeira e mais difusa diz respeito aos economistas que, mesmo sem estarem identificados com o pensamento de Marx, não deixam de reconhecê-lo ou de sentir sua presença, em particular nas assim chamadas questões sociais e em temas associados ao atraso relativo das nações. Nesse sentido genérico, pode-se afirmar que a influência do marxismo atinge inúmeros economistas brasileiros; entre outros, Celso Furtado fez referências atentas às idéias de Marx sobre o desenvolvimento econômico (1).
\end{abstract}

Mas é a uma segunda e mais restrita perspectiva - a dos autores e obras que se propõem a seguir a metodologia e/ou a pauta de reflexões do marxismo - que a análise feita no presente artigo se dirige. Nesse terreno, e a despeito da existência de opiniões ponderáveis em contrário (Konder, 1991; Mantega, 1995), é possível sustentar que a economia política marxista não exerceu um impacto decisivo no pensamento econômico brasileiro (2). O caso foi bem outro: com raras exceções, a obra dos economistas assumidamente marxistas permaneceu imersa no caudal do desenvolvimentismo, raramente se distinguindo e/ou estabelecendo argumentos originais. Estudar as razões dessa falta de identidade e pontuar as raras exceções relevantes, ou seja, identificar sinais de vida no marxismo econômico brasileiro, constitui o objetivo do autor neste trabalho.

Em seu monumental estudo sobre o pensamento econômico brasileiro no ciclo do desenvolvimentismo, Bielschowsky (1988) chamou atenção para a dependência dos economistas socialistas às vicissitudes e aos vaivéns políticos das correntes de esquerda. Posição semelhante foi adotada por Mantega (1987), que propôs até mesmo uma tipologia dos economistas marxistas brasileiros com base na filiação às grandes correntes políticas do marxismo internacional.

As observações destes dois autores apenas confirmam o fato de que, por ser uma doutrina preponderantemente orientada para a ação, o marxismo dificilmente consegue desvincular-se do cenário contingente das lutas políticas e das propostas de transformação social. Nesse particular, no entanto, a diferença entre os autores marxistas e os demais não seria tão marcante, já que os mais proeminentes economistas brasileiros se destacaram justamente pela atenção aos problemas do desenvolvimento nacional e por um certo pragmatismo na reflexão; enfim, por darem importância às circunstâncias políticas. 
A característica do pensamento econômico marxista residiria menos no domínio de sua agenda de investigações pelas circunstâncias políticas, do que na existência de uma moldura partidária na reflexão. De fato, especialmente entre as décadas de 40 e 70, a discussão marxista no Brasil foi muito pautada por ideários e formas de ação partidárias (contra e a favor), pelas idas e vindas do movimento comunista e por um imenso apetite em enfrentar controvérsias internas às correntes de esquerda. Menos afetados pelos compromissos partidários e mais comprometidos com a execução da política econômica e/ou com a visão dos organismos internacionais de desenvolvimento econômico, os economistas não-marxistas foram mais pragmáticos na ação.

Paradoxalmente, é um certo pragmatismo que ajuda a explicar a subordinação dos autores considerados marxistas ao receituário desenvolvimentista. Nos anos 50 e 60, um período de grandes transformações na economia e crucial para a formação do pensamento econômico brasileiro, foram poucos os economistas de esquerda que deixaram de assumir o programa de "reformas estruturais" do desenvolvimentismo, inclusive a explicação estruturalista do processo inflacionário (Bielschowsky, 1988). Essa atitude reflexa não deixa de revelar um certo pragmatismo: por acreditarem que a análise da CEPAL dava substância aos programas partidários da esquerda, centrados na defesa dos capitais nacionais e na luta contra o arcaísmo rural, os marxistas e socialistas adotaram-na sem maiores problemas.

A subordinação ao desenvolvimentismo revela também a pequena criatividade do marxismo brasileiro. Com poucas e notáveis exceções, até a década de 70, os marxistas brasileiros não dispunham de qualquer explicação própria e relevante para o subdesenvolvimento latino-americano e nacional. Essa falta de desenvoltura se explica por duas razões. Em primeiro lugar, a partir dos anos 30 a economia política marxista deixou de ser um ramo teórico florescente no plano internacional. O relativo isolamento, a falta de intercomunicação com os segmentos mais destacados do pensamento econômico e o próprio declínio do marxismo ocidental, responsáveis pela atrofia da economia política marxista em todo o mundo, não poderiam deixar de afetar o marxismo nos países da periferia.

Em segundo lugar, até os anos 60, Marx parece ter sido quase um desconhecido no Brasil (Arantes, 1995). A tardia formação de círculos de leitura e de reflexão do marxismo clássico bloqueou a afirmação e difusão de uma forma de pensamento que se nutre da recorrência às obras magistrais. Para culminar, a maré montante do marxismo no pensamento social brasileiro, iniciada nos anos 60 , não chegou a se estender ao território da Economia. A rigor, o marxismo só exerceu alguma influência nos estudos de Desenvolvimento Econômico, pouco penetrando nos demais ramos da Economia Geral e Aplicada, inclusive na Política Econômica. 


\section{Desenvolvimento Econômico}

Embora neste artigo não se trate da influência do marxismo na historiografia brasileira, é importante notar que existe apenas uma tênue linha de demarcação entre a História Econômica e o Desenvolvimento Econômico. Se entendermos este último, de modo genérico, como uma reflexão voltada à identificação de sentidos, de linhas de continuidade e de rupturas na trajetória econômica nacional, o interesse nos momentos de descontinuidade econômica será facilmente entendido. História Econômica e Desenvolvimento Econômico compartilham temas centrais para o entendimento das descontinuidades, como o fim do escravismo, a constituição do mercado de trabalho livre, a emergência da industrialização, as modificações nas relações internacionais etc.

O fato é que os estudos marxistas sobre o desenvolvimento econômico sofreram pouca influência da pesquisa histórica inspirada no marxismo por uma razão trivial: o florescimento relativamente tardio do marxismo histórico no Brasil. Exceção feita à iniciativa exemplar de Caio Prado Júnior (1942) e a poucos esforços isolados, como o de Nelson Werneck Sodré (1962), foi apenas ao final da década de 70 , e por meio de uma nova onda de estudos sobre a escravidão, que houve uma penetração marcante da perspectiva marxista na investigação histórica. Esta onda, mesmo tendo ensejado a adaptação ao cenário brasileiro de temas clássicos do marxismo (3) e a formulação de conceitos originais, como o de modo de produção escravista-colonial (Gorender, 1978), foi posterior ao surgimento do interesse pela perspectiva marxista nos estudos de desenvolvimento econômico.

Os estudos que abordam o desenvolvimento econômico brasileiro a partir de uma perspectiva marxista surgiram, rigorosamente, em contraposição ao modelo estruturalista de desenvolvimento econômico. Vale lembrar que o texto decisivo na difusão do estruturalismo no Brasil, Formação econômica do Brasil, de Celso Furtado (1959), é uma interpretação da história econômica. Este livro tornou-se leitura obrigatória nos cursos de economia e um ponto de referência para as discussões sobre o desenvolvimento econômico brasileiro, vindo a influenciar decisivamente a reflexão marxista dos anos 70 .

Os trabalhos de Sergio Silva (1976), João Manuel Cardoso de Mello (1985) e Ignácio Rangel (2000) são três bons exemplos do que aqui se denomina de estudos de desenvolvimento econômico influenciados pelo marxismo. A temática 
destes trabalhos é a da industrialização; no caso de Rangel, trata-se de ensaios sobre as implicações da transformação de uma economia agrária em urbano-industrial.

Antes de uma referência mais detalhada a cada uma destas contribuições, cabe assinalar que a industrialização, não por acaso, tornou-se uma questão decisiva para os autores marxistas. É sabido que $O$ Capital tem como pano de fundo histórico a Revolução Industrial e as transformações por ela promovidas. Marx foi ainda além: para ele, as "leis gerais de movimento da economia capitalista" - objeto central de $O$ Capital - dependem da prévia constituição de forças produtivas e de relações sociais capitalistas, associadas ao domínio da grande indústria. Desse modo, não há como um estudioso do desenvolvimento econômico brasileiro sob a influência do marxismo deixar de se preocupar com as circunstâncias da industrialização; mais ainda de uma industrialização que foi tardia em relação às experiências dos países centrais e dotada de características específicas.

Talvez o trabalho de Sergio Silva represente a mais original das interpretações da industrialização brasileira com base no marxismo. A originalidade de $E x$ pansão cafeeira e origens da indústria no Brasil (publicado em 1976, a partir de tese apresentada em 1973) não decorre somente do tratamento de certo modo pioneiro dado às relações entre café e indústria. Decorre, principalmente, da capacidade de reconstituir a natureza do processo de industrialização brasileiro, com grande economia de meios e a partir de poucas noções substanciais. Estas noções - industrialização como um processo social, desenvolvimento desigual, transição e subordinação do trabalho ao capital -, tomadas de Marx sob o filtro da interpretação de Charles Bettelheim, permitiram a Sergio Silva destacar o papel decisivo da diversificação da economia cafeeira paulista na industrialização, mesmo com o apoio de uma fundamentação histórica bastante restrita. Note-se que a fundamentação histórica de Expansão cafeeira vai pouco além dos conhecidos trabalhos de Emília Viotti da Costa, Warren Dean, Nícia Vilela Luz, Celso Furtado e Caio Prado Júnior.

O capitalismo tardio (publicado em 1982, a partir de tese apresentada em 1975), de João Manuel Cardoso de Mello, evidencia a influência das idéias de Celso Furtado e da cepal no pensamento econômico brasileiro. Em seu trabalho, que tem como ponto de partida a crítica ao modelo centro-periferia, Mello pretendeu não só fornecer uma explicação distinta da de Celso Furtado para as origens da industrialização brasileira, mas também oferecer uma nova caracterização da industrialização, bem como cunhar uma periodização própria do desenvolvimento econômico brasileiro, apoiada na concepção marxista de forças produtivas.

A exemplo do que ocorrera no trabalho de Silva, O capitalismo tardio refere as origens da industrialização brasileira à diversificação da economia cafeeira e ao 
transbordamento do capital cafeeiro pelos vários segmentos da economia regional paulista. O fundamental no trabalho, no entanto, é a caracterização das etapas do desenvolvimento econômico brasileiro, que se baseia em dois elementos: por um lado, em uma revisão da noção de industrialização, entendida como um processo de implantação de "forças produtivas capitalistas"; por outro, em uma peculiar caracterização das "forças produtivas especificamente capitalistas", que as associa à montagem de um setor interno de bens de produção. Para Mello, a trajetória do desenvolvimento econômico brasileiro seria a de constituição de "forças produtivas especificamente capitalistas", no sentido aludido.

Cabe observar que, ressalvado o uso de categorias marxistas, a caracterização de "forças produtivas especificamente capitalistas" adotada acaba por definir uma trajetória para a industrialização brasileira que, ao fim e ao cabo, não difere inteiramente daquela imaginada pelo estruturalismo. Não é estranha à CEPAL e, particularmente, a Furtado (4), a visão de uma industrialização que se vai complementando até a completa diversificação; explicitamente, até a incorporação de um setor de bens de produção. Enfim, a despeito do uso de categorias marxistas, a dinâmica das forças produtivas de $O$ capitalismo tardio não deixa de representar a transliteração de uma démarche que fora proposta por Celso Furtado nos termos do estruturalismo.

Inspiração totalmente diferente é a de Ignácio Rangel. Não estamos nos referindo aqui à clássica interpretação do processo inflacionário de $A$ inflação brasileira, que pertence ao domínio da Economia Aplicada e da Teoria da Política Econômica e nada deve ao marxismo (5). Referimo-nos à concepção de desenvolvimento econômico presente nos diversos textos de Rangel sobre a questão agrária, escritos nos anos 50, 60 e 70, recentemente reeditados em Questão agrária, industrialização e crise urbana no Brasil. Estes textos partilham uma visão complexa do desenvolvimento econômico, envolvendo o progresso técnico, a urbanização e um peculiar entendimento da redistribuição do trabalho social.

A originalidade de Rangel reside menos na conhecida tese da "dualidade básica" do que na inovadora abordagem dada à tradicional questão do desenvolvimento econômico com excedente de mão-de-obra. Tendo como referência a dinâmica entre tempo de trabalho ocupado e tempo de trabalho desocupado (nas atividades agrícolas e não-agrícolas), Rangel propõe uma explicação original - e que muito deve ao marxismo - para a crise urbana associada à industrialização brasileira. Note-se que Rangel deve ao marxismo não a noção de dualidade, mas uma concepção de desenvolvimento fundamentada na alocação do trabalho social, diretamente inspirada em Desenvolvimento do capitalismo na Rússia, de Lênin. O marxismo, na versão de Lênin, fundamenta a interpretação única de Rangel a respeito da passagem da economia agrária à urbano-industrial. 


\section{Economia Aplicada e Política Econômica}

Dois grandes conjuntos de temas imantaram o pensamento econômico brasileiro na segunda metade século XX: a industrialização, o desenvolvimento econômico, o protecionismo e a política cambial; a estabilidade macroeconômica. $\mathrm{O}$ primeiro conjunto foi especialmente representativo do pensamento econômico no imediato pós-guerra, mantendo-se em destaque até o final dos anos 60. Já o segundo conheceu dois auges, correspondentes aos dois surtos de aceleração inflacionária e às políticas de estabilização a eles associadas (1959-64; 1982-95). No primeiro auge inflacionário houve uma certa superposição entre os dois conjuntos temáticos, já que alguns diagnósticos da inflação apontavam para as condições "estruturais" da economia.

O fato de pouco ter contribuído para o debate destes dois conjuntos de temas revela a debilidade do pensamento econômico marxista no Brasil. Com relação à industrialização, ao desenvolvimento econômico e à política cambial, as abordagens marxistas mais relevantes, como foi dito na sessão anterior, vieram em resposta às interpretações estruturalistas, e com atraso no que se refere ao fato histórico (exceção feita à intervenção de Ignácio Rangel). Por mais relevantes que tenham sido suas conclusões, os economistas marxistas se dispuseram a refletir sobre a industrialização depois que ela já ocorrera, tendo por isso se limitado a sistematizar o passado.

Uma revisão dos artigos econômicos publicados em dois dos mais importantes periódicos de divulgação do pensamento socialista, a Revista Brasiliense e a Revista Civilização Brasileira, testemunha essa relativa incapacidade em participar no debate de assuntos econômicos mais gerais. A Revista Brasiliense, editada regularmente de 1955 a 1962, publicou diversos artigos sobre tópicos econômicos específicos, como agricultura, política salarial, participação do capital estrangeiro nas concessões de serviços de utilidade pública (o que era relacionado ao imperialismo), apoio à indústria nacional. Foram quase sempre intervenções pontuais, antes expressando a opinião política da esquerda sobre a conjuntura e as divergências entre as correntes da esquerda, do que sistematizando o resultado de novas investigações, ou até mesmo revelando empenho na aplicação da teoria marxista aos fatos econômicos brasileiros. Caio Prado Júnior, editor da Brasiliense e o mais capacitado dos intelectuais marxistas brasileiros, dispersou seus esforços em pequenas intervenções políticas e em textos didáticos sobre a teoria econômica marxista, afora as relevantes contribuições sobre a agricultura brasileira (a serem mencionadas mais adiante).

A Revista Civilização Brasileira, editada entre 1965 e 1968, refletiu em suas matérias econômicas a oposição ao governo militar, na forma de uma crítica à política econômica Campos-Bulhões. A maior parte dos artigos da Civilização 
Brasileira manteve-se impregnada do pessimismo crônico das visões estagnacionistas, tornadas canônicas por Celso Furtado (1966) e amplamente aceitas nos meios estruturalistas e de esquerda até a taxativa contestação de Maria da Conceição Tavares e José Serra (1971). Revista numa perspectiva histórica, a recessão do início dos anos 60 não parece justificar o elevado pessimismo e muito menos o viés estagnacionista das críticas da esquerda. Mas o mais curioso - e até mesmo emblemático - foi o fato de um raro exemplar de artigo contendo uma explicação inovadora da inflação e da queda da taxa de crescimento, não-referida ao estagnacionismo, vir a ser violentamente contestado pelos "marxistas", a despeito de ter sido elaborado por um deles.

O artigo em questão é “Ciclos de conjuntura em economias subdsenvolvidas", no qual Paul Singer (1965) descartava a concepção de estagnação estrutural em favor da hipótese - afinal revelada verdadeira - de que a economia brasileira atravessava uma prosaica fase de declínio no ciclo de conjuntura. Neste artigo, Singer procurava distinguir as características do ciclo em economias maduras e atrasadas, em busca de uma explicação para a inflação brasileira amparada na teoria econômica.

Dois números após a publicação deste artigo, uma réplica de Assis Tavares (1965) focalizou o que se pode considerar a posição oficiosa do Partido Comunista Brasileiro, revelando o triste estado do marxismo dominante. Em nome do marxismo, Tavares negava o caráter conjuntural da crise econômica e do surto inflacionário, reafirmando a tese de que as raízes estruturais da inflação residiam na concentração dos meios de produção e no subseqüente bloqueio ao desenvolvimento das forças produtivas. Descabida e mal fundamentada, a crítica de Assis Tavares revelava uma postura típica dos anos 60, com os economistas de esquerda ecoando o pessimismo estagnacionista e reafirmando o postulado estruturalista de que a inflação era estrutural, e reservando-se o direito de acrescentar o condimento "marxista" da luta de classes e da exploração.

Afora o artigo de Singer, poucas contribuições inspiradas pelo marxismo em economia geral merecem destaque nas décadas de 60 e 70 . Digno de nota é o trabalho de Maria da Conceição Tavares (6), que aplicou com muita originalidade os esquemas departamentais kaleckianos à economia brasileira, combinando a influência de Marx-Kalecki a modernas concepções de finanças e de organização industrial.

Antônio Barros de Castro foi outro autor que também se destacou por aplicar o marxismo e o neomarxismo norte-americano aos problemas econômicos do pós-guerra, mas seus ensaios mais referidos ao marxismo (Castro, 1979) estavam voltados ao panorama econômico internacional e às economias desenvolvidas (7). 
Em momento posterior, as inúmeras teses e interpretações que acompanharam o surto inflacionário 1982-94 nem de longe se aproximaram do marxismo. O surto inflacionário iniciado na década de 80 , subproduto de uma crise do padrão internacional de financiamento que atingiu diversos países da América Latina e provocou pressões inflacionárias disseminadas, levou o foco de atenteórica do período

foi a hipótese da inflação inercial ... ção dos economistas para a política macroeconômica. No caso brasileiro, a combinação entre dificuldades no financia-

mento externo e inconsistências no financiamento do setor público, a par dos sinais evidentes de esgotamento do sistema de indexação construído nos anos 60 e 70, criaram um cenário que pouco animava a construção de hipóteses "estruturais" sobre a inflação. Ao contrário, os economistas convergiram para as discussões fiscais, cambiais e de política monetária, digladiando-se em torno das políticas macroeconômicas capazes de enfrentar a pressão inflacionária. Nesse terreno, o marxismo tinha muito pouco a ensinar. A grande novidade teórica do período - e a maior fonte de controvérsias e de pesquisa entre os economistas - foi a hipótese da inflação inercial.

A irrelevância da perspectiva marxista nos debates sobre a inflação dos anos 80 e 90 é sugestiva. Se, por um lado, ela refletia o estiolamento da teoria econômica marxista em todo o mundo, por outro revelava uma falta de atenção dos economistas heterodoxos brasileiros (e não apenas dos marxistas) ao fenômeno inflacionário e às políticas de estabilização. No território acadêmico nacional, as discussões sobre a inflação trafegaram quase exclusivamente entre a FGV, a PUC e outras poucas instituições exclusivamente influenciadas pelo mainstream econômico. Mesmo o muitas vezes denominado "pensamento heterodoxo" em matéria de inflação, vale dizer, as críticas à visão monetarista do final da década de 70 e início dos anos 80 , bem como as análises e propostas decorrentes da visão de inflação inercial, tiveram como patrono inegável Mário Henrique Simonsen. Nada mais longe do marxismo...

\section{Economia do trabalho e questão agrária}

No rol dos tópicos especiais relativos à economia brasileira, merecem atenção as contribuições marxistas à economia do trabalho e à economia rural. Em economia do trabalho, exemplos sugestivos da influência marxista encontram-se nos trabalhos de Francisco de Oliveira, Paul Singer e Paulo Renato de Souza. Também merecem atenção as diversas análises sobre o processo de trabalho inspiradas em Marx. 
A Crítica à razão dualista, de Oliveira (1972), um monumental ataque à economia política da CEPAL e um esforço de reconstituição da lógica da industrialização brasileira e da política econômica da era Vargas, utiliza hipóteses marxistas sobre mercado de trabalho e custo de reprodução da força de trabalho para interpretar a racionalidade da política de salário mínimo adotada por Vargas.

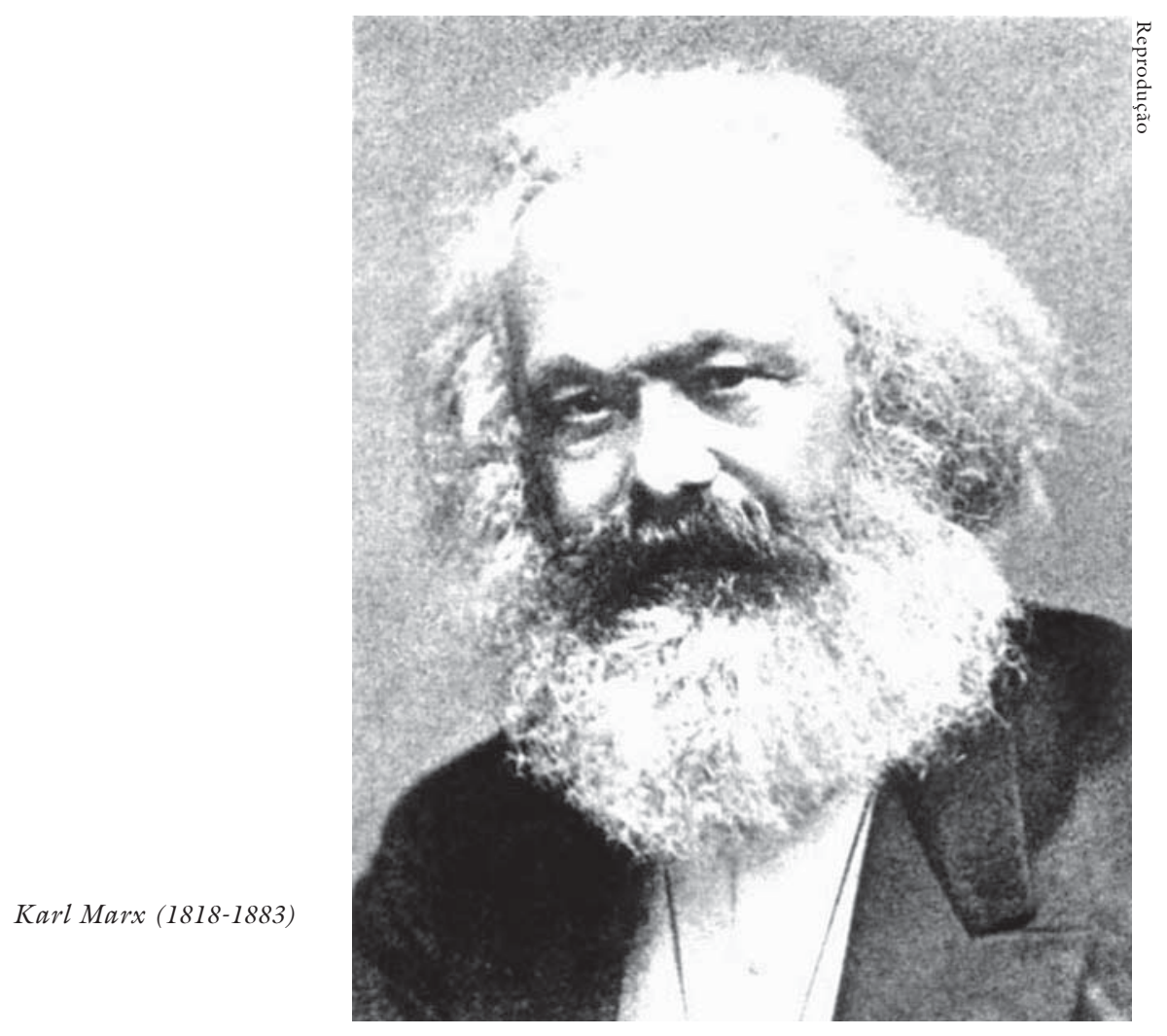

Por sua vez, Paul Singer, em Economia politica do trabalho (1977), já procurava formular uma teoria do emprego aplicável a países não-desenvolvidos, com extensa referência ao marxismo e a outras teorias do emprego e do trabalho. A teoria de Singer notabilizou-se pela presença de fortes elementos demográficos, bem como pelas controvertidas hipóteses sobre os modos de produção na economia brasileira.

Os trabalhos de Souza (1980a; 1980b) representaram uma retomada das pesquisas sobre a informalidade no mercado de trabalho latino-americano, desenvolvidas inicialmente pela OIT-PREALC. Valendo-se da noção marxista de exército industrial de reserva, Souza procurou entender os nexos entre o mercado de trabalho formal e o informal.

Por seu lado, os estudos sobre o processo de trabalho tiveram por base a detida análise do tema por Marx em O Capital. O estudo de caso sobre a indús- 
tria do açúcar de José Sérgio Leite Lopes (1976), O vapor do diabo, oferece uma combinação original entre o enfoque econômico de inspiração marxista sobre o processo de trabalho e a perspectiva antropológica. Dentre diversas outras pesquisas sobre o processo de trabalho na indústria, efetuadas por historiadores, sociólogos, economistas e até mesmo engenheiros, merece destaque o programa liderado por Cândido Guerra Ferreira no CEDEPLAR/UFMG. A própria tese doutoral de Ferreira (1986) constitui um exemplo significativo de aplicação do enfoque regulacionista/marxista a um segmento da indústria (no caso, a siderurgia).

No entanto, foi à Economia Rural que os economistas marxistas brasileiros mais se aplicaram no pós-guerra. A ligação dos marxistas com os estudos agrários não se deve apenas à elevada importância da agricultura na economia brasileira, até o final dos anos 50. Deve-se também muito à fermentação do debate sobre a reforma agrária no Brasil e, sobretudo, à posição estratégica da questão agrária no pensamento marxista sobre as relações sociais e o atraso econômico. Em Marighella et al. (1980) encontra-se um painel diversificado dos debates sobre a questão agrária do final dos anos 50 e início dos 60, bastante influenciados pelo marxismo.

Os trabalhos de referência sobre a questão agrária foram os de Alberto Passos Guimarães, Ignácio Rangel e Caio Prado Júnior (8). Guimarães (1963a) notabilizou-se por atribuir às relações sociais no campo um caráter feudal ou semifeudal, e por enfatizar a característica latifundiária da propriedade rural brasileira. Dessa interpretação decorreram tanto propostas específicas de reforma agrária, quanto uma peculiar visão da inflação brasileira, centrada na concentração dos meios de produção (Guimarães, 1963b).

Concordando com a natureza feudal ou semifeudal do agro brasileiro, mas divergindo das propostas de reforma agrária em evidência no início da década de 60, colocou-se Ignácio Rangel (2000). Vale lembrar que Rangel recorreu a uma explicação particular do papel da intermediação agrícola na formação dos preços, associada à análise da questão agrária, em sua celebrada interpretação da inflação brasileira. Como foi dito, a posição de Rangel sobre a questão agrária denota, antes de mais nada, um entendimento específico e sofisticado do desenvolvimento brasileiro, referido à distribuição do trabalho social e aos mecanismos de adaptação criados na passagem da economia agrária à urbana.

Nessa discussão, a posição de Caio Prado Júnior merece destaque por razões especiais. Em primeiro lugar, por ter sido inteiramente articulada a seus estudos de história econômica, que chamam atenção para a racionalidade empresarial do latifúndio agrícola nos diversos momentos da história brasileira, sob os mais diversos regimes de contratação de mão-de-obra. Em segundo lugar, pelo fato de que, ao negar o caráter semifeudal das relações sociais e enfatizar o papel do assalariamento na agricultura, Caio Prado Jr. (1966) tornou-se um dos pivôs intelectuais de um forte movimento de rejeição e de ruptura com as interpreta- 
ções adotadas pelo Partido Comunista Brasileiro. Transbordando da questão agrária para a discussão da estratégia revolucionária como um todo, esta ruptura teve conseqüências decisivas na história política da esquerda brasileira. Do ponto de vista da produção intelectual, refletiu-se diretamente nas teses de Rui Mauro Marini (1968, 1969) sobre superexploração e subimperialismo, e de Theotônio dos Santos (1970) sobre a dependência.

A influência dos estudos agrários de Caio Prado Jr. também se fez sentir em uma nova geração de estudos universitários sobre a agricultura e a questão agrária. A rigor, o pensamento marxista teve um papel central na revitalização das pesquisas sociológicas, históricas e econômicas sobre a estrutura agrária e a dinâmica da agricultura brasileira, marcada pela atenção conferida à diversidade das relações sociais no campo. Nesta nova geração de trabalhos sobre a agricultura e a questão agrária, as perspectivas histórica, sociológica e econômica estão muitas vezes combinadas, sendo impossível distinguir uma agenda de investigações exclusiva dos economistas. Os trabalhos de Gnaccarini (1980), Souza Martins (1975; 1979), Cardoso (1979) e Linhares e Teixeira (1981), são referências expressivas desta nova frente de investigações acadêmicas, de natureza interdisciplinar (9).

\section{Notas}

1 Especialmente, Furtado (1961; 1967).

2 Por pensamento econômico brasileiro entendemos o pensamento voltado à discussão da economia brasileira. Neste artigo não são tratados os diversos livros e artigos de autores brasileiros sobre Marx e a economia marxista.

3 Entre eles, cabe citar os dos modos de produção (Cardoso, 1979; Gorender, 1978), das relações entre as economias coloniais e o capitalismo em formação (Novais, 1979), dos processos de trabalho (Castro, 1976) e das formas de riqueza e acumulação (Fragoso \& Florentino, 1993).

4 Ver em especial Formação econômica do Brasil (1959) e o notável ensaio introdutório de 1954, A economia brasileira.

5 Apesar de a opinião em contrário de Bresser Pereira. Veja-se Rangel (1978), Prefácio à $3^{a}$ edição de $A$ inflação brasileira.

6 Em especial Tavares (1978).

7 Exceção feita à mencionada pesquisa histórica sobre a escravidão (Castro, 1976).

8 Bielschowsky (1988) fez uma revisão das principais contribuições dos economistas ao debate sobre a questão agrária brasileira nas décadas de 50 e 60 .

9 Gnaccarini \& Moura (1990) apresentam um balanço das pesquisas sobre estrutura agrária brasileira nas décadas de 70 e 80 . 
Referências bibliográficas

ARANTES, P. Origens do marxismo filosófico no Brasil. In: Moraes, J.Q. (org.), História do marxismo no Brasil, v. II. Campinas, Ed. Unicamp, 1995.

BIELSCHOWSKY, R. Pensamento econômico brasileiro - o ciclo ideológico do desenvolvimentismo. Rio de Janeiro, IPEA, 1988.

CARDOSO, C. F. Agricultura, escravidão e capitalismo. Petrópolis, Vozes, 1979.

CASTRO, A. B. Escravos e senhores nos engenhos do Brasil. Campinas, 1976. Tese (doutoramento), Instituto de Economia, Unicamp, 1976 [mimeo.].

O capitalismo ainda é aquele. Rio de Janeiro, Forense, 1979.

FERREIRA, C.G. Procès de travail et rapport salariel dans l'industrie sidérurgique: étude de la formation des normes mondiales et du cas Brésilien. Paris, 1986. Tese (doutorado), Université de Paris [mimeo.].

FRAGOSO, J. \& FLORENTINO, M. O arcaísmo como projeto. Rio de Janeiro, Diadorim, 1993.

FURTADO, C. A economia brasileira. Rio de Janeiro, Ed. A Noite, 1954.

1959.

Formação econômica do Brasil. Rio de Janeiro, Fundo de Cultura,

Cultura, 1961.

Desenvolvimento e subdesenvolvimento. Rio de Janeiro, Fundo de

Subdesenvolvimento e estagnação na América Latina. Rio de. Janeiro, Civilização Brasileira, 1966.

Teoria e política do desenvolvimento econômico. São Paulo, Companhia Editora Nacional, 1967.

GNACCARINI, J.C. Latifúndio e proletariado: formação da empresa e relações de trabatho no Brasil rural. São Paulo, Polis, 1980.

GNACCARINI, C. \& MOURA, M. Estrutura agrária brasileira: permanência e diversificação de um debate. In: O que se deve ler em Ciências Sociais no Brasil. São Paulo, ANPOCS/Cortez, 1990.

GORENDER, J. O escravismo colonial. São Paulo, Ática, 1985.

KONDER, L. Intelectuais brasileiros e o marxismo. Belo Horizonte, Oficina de Livros, 1991.

LEITE LOPES, J.S. O vapor do diabo: o trabalho dos operários do açúcar. Rio de Janeiro, Paz e Terra, 1976.

LINHARES, M.Y. \& SILVA, F.C.T. História da agricultura brasileira: combates e controvérsias. São Paulo, Brasiliense, 1981. 
MANTEGA, G. A economia politica brasileira. Petrópolis, Vozes, 1984.

Marxismo na economia brasileira. In: Moraes, J.Q. (org.), História do marxismo no Brasil, v. II. Campinas, Ed. Unicamp, 1995.

MARIGHELlA, C. et al. A questão agrária no Brasil. São Paulo, Brasil Debates, 1980.

MARINI, R.M. Contradições e conflitos do Brasil contemporâneo. São Paulo, Teoria e Prática, n. 3, abr. 1968.

Subdesarrollo y revolución. México, Siglo Veintiuno, 1969.

MARTINS, J. de SOUZA. Capitalismo e tradicionalismo: estudos sobre as contradições da sociedade agrária no Brasil. São Paulo, Pioneira, 1975.

O cativeiro da terra. São Paulo, Hucitec, 1979.

MELLO, J.M.C. O capitalismo tardio. São Paulo, Brasiliense, 1982.

NOVAIS, F.A. Portugal e Brasil na crise do antigo sistema colonial (1777-1808). São Paulo, Hucitec, 1978.

OLIVEIRA, F. A economia brasileira: crítica à razão dualista. São Paulo, Estudos Cebrap n. $2,1972$.

PRADO JR., Caio. Formação do Brasil contemporâneo. São Paulo, Brasiliense, 1942.

RANGEL, I. A inflação brasileira, $3^{a}$ ed. São Paulo, Brasiliense, 1978.

Questão agrária, industrialização e crise urbana no Brasil. Porto Alegre, Editora da Universidade Federal do Rio Grande do Sul, 2000.

SANTOS, T. Dependência y cambio social. Santiago, CESO, 1970.

SILVA, S. Expansão cafeeira e origens da indústria no Brasil. São Paulo, Alfa-Ômega, 1976.

SINGER, P. Ciclos de conjuntura em economias subdesenvolvidas. Rio de Janeiro, Revista Civilização Brasileira, n 2, 1965.

SODRÉ, N. W. Formação histórica do Brasil. São Paulo, Brasiliense, 1962.

SOUZA, P.R. A determinação dos salários e do emprego nas economias atrasadas. Campinas, 1980a. Tese (doutoramento), Instituto de Economia, Unicamp, 1980 [mimeo.]. Emprego, salários e pobreza. São Paulo, Hucitec/Funcamp, 1980 b.

TAVARES, A. Crise de conjuntura e crise de estrutura. Rio de Janeiro, Revista Civilização Brasileira, n 2, jan. 1965.

TAVARES, M.C. Ciclo e crise: o movimento recente da industrialização brasileira. Rio de Janeiro, 1978. Tese (titularidade), Universidade Federal do Rio de Janeiro [mimeo.].

TAVARES, M.C. \& SERRA, J. Mas allá del estancamiento: una discussión sobre el estilo de desarrollo reciente. Mexico, El Trimestre Económico, v XXXVIII, n 52, 1971. 
RESUMO - NO ARTIGO é feito um balanço da influência do marxismo no pensamento econômico brasileiro no pós-guerra. É dado um especial destaque aos estudos sobre Desenvolvimento Econômico Brasileiro, bem como aos trabalhos em Economia do Trabalho e Questão Agrária, áreas que reúnem o núcleo mais expressivo de contribuições marxistas. $\mathrm{O}$ artigo conclui pela pequena relevância do pensamento econômico marxista no Brasil, em particular no que se refere às discussões sobre Economia Geral e Política Econômica.

ABSTRACT - THE PAPER is concerned with the influence of marxism in Brazilian economic thought. Economic Development, as well as Labor Economics and Agrarian Studies, are the focuses of our attention, since these are the issues in which marxism has had a broader influence. In a general appraisal, it is arguable that marxism has had no impacting influence in Brazilian economic thought, particularly in what refers to General Economics and Economic Policy studies.

Maurício Chalfin Coutinho, professor do Instituto de Economia da Universidade Estadual de Campinas (Unicamp), tem publicado e vem se dedicando a pesquisas em História do Pensamento Econômico e Economia do Setor Público.

O autor agradece a atenção e as opiniões de João Antonio de Paula, Tamás Szmrecsányi e José Graziano da Silva. Destaca que as idiossincrasias e eventuais equívocos são de sua inteira responsabilidade. 